\title{
Special Aspects of Criminal Activity in the Field of Public and Municipal Procurement
}

\author{
Ekaterina Tishchenko*
}

Southern Federal University, Rostov-on-Don, Russia; tok_mak@mail.ru

\begin{abstract}
Objectives: In this work, the complex debate on risk perception is combined with its assessment, but from the standpoint of behavioral choice theories. Method: Traditional methods of research are not able to fully reveal the role of the individual characteristics of criminal risk subjects. The authors looked into socio-perceptual mechanisms of public procurement participants and resorted to the 'red flags' and 'crime hotspots' methods to clarify regularities at the individual level of deviant behavior in order to minimize them and to develop coping strategies Findings: Criminal risks of the national public procurement system have been audited; typical criminal risks arising in all procurement stages both on the part of customers and on the part of other parties have been theoretically diagnosed. The original hypothesis of an exclusively deliberate choice of criminal behavior has been confirmed in part. Improvements: The findings presented in the paper can help increase the detection of crimes in the area of public procurement, enhance the efficiency of investigations and minimize the scope for criminal abuse.
\end{abstract}

Keywords: Abuse of Power, Abuse of Office, Corruption, Criminal Risks, Fraud, Illegal Business, Misappropriation of Budget Funds, Misappropriation of State Municipal Funds, Negligence, Official Misconduct

\section{Introduction}

The area of public procurement is largely exposed to diverse risks of crimes at different stages of procurement. Based on forensic investigative practices, the criminological literature provides an active analysis of the situation in the system of public procurement, which could lead to a criminal risk occurrence. As a rule, it is limited to formulating corruption indicators. The authors believe that not all the risks are directly related to corruption, and that it is necessary to take other 'hot spots' into account

The modern system of public and municipal procurement, serving as the main mechanism of budget spending to meet social needs, is a special cross-sectoral area of economic activity of the state, municipalities, businesses and institutionalized civil society actors. The crimes committed in the area of public procurement are noted for a high social danger, as they represent a direct threat to the comfortable investment climate development in the country, the stability of its domestic financial system, including at the international level, as well as well-being of the population as a whole.
This requires interdisciplinary research, i.e. economic and legal, economic and sociological, and others; the variety of risks in the field of public procurement determined by both the contradictory interests of its subjects and complexity and graduality of procurement procedures. Procurement implementation includes a number of distinct phases, such as placing the notice, filing bid applications and price offers, selecting and contracting a winner, fulfillment of obligations under the contract. Managerial decision-making at any of these stages is attended by multiple risks, including criminal ones.

Analysis of enforcement activities and theoretical views shows that practice-oriented authors are focused on studying in particular economic criminal schemes and mechanisms in the field of procurement. 2 As a rule, this is a study of fraudulent schemes: property theft and falsification of identification documents and call of business security professionals. Dr. Wells' scientific views have even ultimately led to creating the Anti-Fraud Association. Or this is a study of criminal 'vulnerability' of corporations and, accordingly, a review of corporate security programs as part of corporate governance. 
Most of the studies are aimed at understanding the crime of corruption component in the procurement system. In these scientists' work the problems of procurement risk level assessment are considered through the lens of severe business climate circumstances in organizations and consolidation trends in various industries, globalization and widespread use of technology in a cycle of accounts payable, outsourcing distribution. At the same time the study of anti-competitive behavior of all the actors (not only officials) of procurement relations through the lens of scientific understanding of 'risk' was not conducted.

In today's world, due to the intensity of potentially risky situations affecting the whole of human existence, the perception of 'risk' category only from the standpoint of economic science becomes archaic. At the turn of 19-20 centuries heuristic theories appear that define the existential nature of risk differently: not only in the economic and legal aspects, but also as a phenomenon of social and cultural life of a person. Modern communication involves a choice between alternatives, which is risky in itself. Thus, the problem of 'risk selection' under the influence of 'a complex set of circumstances' comes to the forefront. Accordingly, a significant role is given to the subject, since there is no risk-free behavior, as well as there is no absolute security. At the same time, different social groups, taking into account the quality of information they possess, have different risk selection criteria at their disposal.

In this context, crime in public procurement has been progressively transforming into a more complex phenomenon. Factors contributing to the existence of risks in the field of study are the state's economic and legislative policies, needs planning quality, procurement relevance and their financial security, rationality or irrationality of customers' activities, business activities for the implementation of a government contract, the quality of fulfilling its conditions. It becomes extremely important to understand criminal situations and vulnerabilities of modern procurement, trends of criminal risks and to develop measures to minimize them.

\section{Method}

To audit criminal risks in the public procurement system, traditional methods of research are used: functional method of information gathering, system analysis method, comparative, structural, expert-analytical comparison methods. But they are not able to fully reveal the role of the individual characteristics of criminal risk subjects. Following descriptive methods, the authors looked into socio-perceptual mechanisms of public procurement participants, that is, the ways in which people understand, interpret and evaluate themselves, and external circumstances in the sphere in question. Herewith, the operationalization focus has been extended to all stages of the procurement process. Then, based on the analysis of criminological literature and jurisprudence, the authors of this study resorted to the 'red flags and 'crime hotspots' methods to clarify regularities at the individual level of deviant behavior in order to minimize them and to develop coping strategies.

\section{Results}

\subsection{The Conceptual Basis for Understanding Criminal Risk and a Criminal Risk Subject}

Formation of scientific knowledge about risk is prolonged in nature, but so far the definition of 'risk' as a general methodological category in view of its multidimensionality has encountered certain difficulty. Based on an analysis of various approaches to the definition of 'risk' notion, the authors adhere to the conception of criminal risk as the activity of a particular subject carried out in conditions of the objective reality on the basis of mental (conscious) assessment of the probability of certain consequences as a result of the acts committed in order to achieve a certain goal, in relation to criminal prohibition. ${ }^{10}$

It acts as an indicator of the highest public danger presence in action or inaction of the parties to a contract, since this is it that points to violation of a prohibitive criminal norm and crime components formation. Procurement risks have been hardly elaborated in the Russian literature. Romanian researchers ${ }^{11}$ presented quite an edifice of public procurement typical risks using the example of the European Union. Given the differences in the legal regulation of the relations in this area, principal risks can be identified at the following stages: 1) goods, works and services procurement planning; 2) procurement; 3) civil contract formation; 4) contract execution.

The criminal risks subject differs from the concept of 'criminal identity', although these concepts are interrelated and often correspond to each other. In criminal science the 
moment a person commits a crime determines qualitative transition from a personality possessing socially dangerous qualities to criminal identity. In this case the social danger of the person is formed, almost always, before the moment of crime. Formation of criminogenic characteristics (traits) in an individual is the result of a long process of its distorted development in a certain (mainly) hostile environment. An act of will to commit a crime is the result of the interaction among three lines of causal relationships: 1) a person's anti-social attitudes, habits, skills; 2) the specific circumstances where the person was before committing the crime; 3 ) the mental model of their act and analysis of its consequences.

The act of choice is always a solution in a variety of opportunities open to a person who chooses. A person does not choose between criminal and noncriminal, but between courses of action called vicious or virtuous depending on the point of view. ${ }^{4}$ The external background (condition), where the parties to a relationship are institutionalized and prove themselves, come into antagonism and make a decision rational for themselves, in this case is a special regulatory, and not only, frame of reference for public procurement. Consequently, imperfection of the legislation, its practical application defectiveness, social and personal interaction perception stigmas are the choice determinants.

Public procurement crimes refer either to economic crime, or to a malfeasance in office. In respect to customers, they can by construed as 'white-collar crime' and crime of the elites. Since procurement is one of the institutions intended to meet the needs of the state and the economy, reference should be made to a close interrelation between malfeasance in office and economic crime where the economic relationship, established in the area of procurement, serve as the condition for criminal encroachment by officials. Symbiotic and other forms of crime, such as mercenary, organized, corporate ones, cannot be excluded either.

\subsection{Monitoring Criminal Risks for Customers in Public Procurement}

The following customer criminal risks can be highlighted.

In the planning phase, there are specification risks, cost risks, bidding method selection risks. Specification risk is influencing the higher agencies and officials for the sake of a purchase inclusion in the plan; economic irrationality of the planned order placement including 'luxury' goods procurement planning; the of lack of coordination between the customers' departments concerning their needs; detecting a 'need' after the budget and extra-budgetary funds allocation. Cost risks include underestimation of the contract price (does not include all the necessary expenses), overestimation of the contract price ('siphoning off' money), other misassessment of the contract price (the estimate is not consistent with the competitive procedures application effects). Bidding method selection risks are characterized by a non-competitive selection procedure resulting from the presence of an alleged legal exception.

At the stage of procuring goods, works and services, there are competence risks, disclosure risks, procedure risks, and collusion risks. Competence risks are related to the situations of creating committees (tender, auction, bidding or unified ones) which include persons who do not have expertise in this area, or with violations of the requirements to these committees' creation. Disclosure risks are related to confidential information disclosure situations. Procedure risks are found in cases of infringing the procedures while opening envelopes. Collusion risks involve situations where the order placement participants, as well as customers in some cases, reach an agreement on who will be the winner, and 'kickbacks' schemes. At a later stage, it is implemented so that the tender process does not comply with the legal structure in order to ensure the 'affiliated' party's victory.

At the contracting stage, there are authority risks, and adaptation risks. Authority risks arise when the contract is signed by a person whose credentials are not properly supported. Adaptation risks are related to situations of sending and signing contracts on terms different from the way they are to be determined according to the law.

At the contract execution stage, there is control risk. As a rule, inefficient cost, quality, and terms monitoring system functioning at the acceptance of the goods delivered, works performed, or services provided leads to this risk. According to the research, in many cases, it is in such a situation where acceptance by the customer of undelivered goods, outstanding works or services is allowed.

Based on an analysis of court sentences via random sampling one can state that municipal officers, as well as health care and construction workers, most frequently appear as defendants in such cases. The crimes are usually committed by the heads (or deputies) of the municipal 
district administration, heads of contractual work and public procurement departments, bidding committee chairmen, on procurement committees' heads.

Customers as the subjects of malfeasance in office are characterized not only by their high social status, but also a powerful administrative resource. The case study clearly illustrates that criminal actions in government contracting are virtually impossible without their direct involvement, whom the specified status allows either to prepare a situation or to give instructions for its criminal preparation. These persons have a fairly high level of education. As is known, the educational level of various offenders' categories is uneven and correlates to the nature of their criminal activities to a certain extent. Almost all the persons brought to account for this category of cases have a higher education. And this relates to the fact that the sphere of providing for a public order is rather complicated, it requires specific knowledge, including for applying criminal schemes and criminal methods. The fairly low ratio of women is noteworthy (10.1\%). Such indication of female criminal activity shows that these social statuses in public procurement are not so much exposed to feminization, unlike trade, banking, and monetary spheres. In the relations under consideration women are actively criminally involved in the health care system.

These persons' need and motivational properties are of interest. These are socially most adapted individuals who tend to stay in the legitimate field, 'seeming' legitimacy. The case materials studied show that quite often the perpetrators do not recognize their guilt (24\%) or excuse themselves of the insignificance or the legal order noncompliance to the external circumstances (19.1\%). The criminal motive consists in the criminal(s)' desire to gain the title (for the benefit of third parties) to someone else's (state/municipal) property. They demonstrate a strongly pronounced opportunistic behavior, which is caused by the fact that a public sector customer has a desire to gain additional profit, and they begin to interfere with the bidding process and its outcomes.

The literature suggests that the increase in the officials' allowance will serve as a deterrent to lucrative inclinations emergence. I $^{\text {f }}$ Unreasonable (and usually quick) enrichment of an official and the conflict of interest are criminal component evidence. Not by coincidence law enforcement officers point out that to solve a crime in this area it often takes one of the parties to be dissatisfied and to begin cooperation with law enforcement agencies.
Criminal transaction 'comfort' is a strong determinant of deviant behavior. 'Comfort' is meant by the participants when all the participants commend the availability of various advantages not prescribed legally. Minimizing criminal risks in this case is possible via eliminating an affiliation between the customer and the performer.

\subsection{Monitoring Suppliers' (Contractors', Performers') Criminal Risks in the Field of Public Procurement}

The following suppliers' (contractors', performers') criminal risks are identified.

At the planning stage, there are funds risks, timing risks. Funds risks arise when the budget figure is deliberately overestimated without actually meeting the liabilities. Timing risks occur in a situation of inconsistency between the planned inter-related procurements.

At the stage of goods, works and services procurement, there are procedure risks, collusion risks. Procedure risks are connected with providing false or grossly procedurally inappropriate documents. On the part of bidders, the possibility of bidders' collusion increases when the tender procedures are not transparent and predictable. Therefore, in the course of tender procedures an unusual composition and distribution of bid applications, high prices, and offers to recourse to sub-contractors in order to solve problems should draw attention in terms of a crime component. When using competitive methods of determining the provider, in particular, such as a contest or an auction, there are potential risks of improper lot formation, incomplete information supply, documentation deficiencies.

At the contracting stage, there is an opportunism risk, when the customer does not send or an order placement party does not sign the contract or signs it failing to enclose enforceability documents. For example, providing a fictitious bank guarantee is a fairly common phenomenon at this stage. Opportunistic behavior also appears at the conclusion of contract with deliberate cost of work or amount of work overstatement, which can in turn cause the indictment of committing a theft. Fraudulent activities at this stage are also quite common, especially from third parties (fictitious firms, banks).

At the stage of contract execution, there are control risks, goal risks. With respect to suppliers (contractors, performers) control risks are manifested in the fraud components formation possibility in business. At the stage 
of payment obligations fulfillment by the customer, an improper organization of budget accounting and arbitrary, in spite of the established order, payment for actually delivered goods, works and services provided, entail goal risks emergence. As the case study shows, wrongdoing in such a risky situation given other constituent features can lead to their being qualified as a diversion of public funds.

It is worth noting that this is quite a 'vulnerable' group in terms of criminal assessment of their acts. Almost at every step of participation in procurement they make mistakes, starting with the receipt of an electronic signature and up to signing the contract. However, on the subjective part a crime in an economic activity area can be committed only intentionally, and in most cases only with direct intent. It is the determination of an intent that is a significant problem for the law enforcement agencies, particularly when the economic activity is simulated as legitimate civil transactions. Short-sightedness in risk aversion, irregularities of financial statements and of the rules of document control, errors, etc. sometimes make it quite troublesome to detect and prove someone's criminal intent. Therefore, in practice, not so many sentences have been passed on suppliers solely.

The case law analysis has shown that most crimes where suppliers act as the subjects are theft by deception and abuse of trust of public and municipal customers. Typical attributes of fraudster's identity are: a male of the most active age (25-45 years old), and in most cases with a rather high level of education, lack of family (or strong ties with family members), and a lucrative motivation for crime.

'Suppliers' refer to a group of swindlers. Posing as extremely competent and capable business people, they skillfully gain confidence, commit fraud to obtain contracts, obligations under which are not going to be fulfilled. Public procurement crimes are associated with the use of modern information, communication, computer technologies. The latter acts as a means to achieve their lucrative goals. But the skills to handle them testify of exceptional abilities, professionalism and criminal 'creativity' of the individuals in question.

Individual personal characteristics of the criminal risk subjects under consideration are for the most part not much different from law-abiding citizens. $60 \%$ of surveyed respondents - participants of public procurement - believe that 'to bribe' is more profitable because: a) everybody does (15\%); b) otherwise it makes no sense to participate
$(20 \%)$; c) required for the good of the cause (5\%). Only $40 \%$ of the respondents shared the opinion that bribery is unacceptable. The rest of respondents were undecided. This forms a persistent delinquent behavior. Further on, having committed a crime, they turn out to fully realize and share the universal moral principles (if they relate to others), but to actively justify their own criminal misconduct. In contrast to lucrative violent criminals, they do not tend to express regret, but they strongly justify and exonerate themselves. They are neither criminal subculture bearers, nor do they identify themselves with the criminal world within its conventional criminal meaning.

The subjects of risk also noted the Russia's contractual system legal framework complexity (45.3\%), the need for recourse to consulting and outsourced companies (78.2\%), which leads to scams activation in this sphere. Our statistical analysis indicates a significant correlation between the level of legal awareness and the activity of fraudulent behavior on the part of indirect (not directly concerned) procurement participants.

It is possible to minimize the risks, on the one hand, by raising legal awareness of contractors, on the other hand, by creating social incentives for good behavior. The court system is an important factor here, which is aimed at ensuring the principle of criminal prosecution inevitability, for officials above all. It must act without selective attitude. Not until then participants form the position of 'profitability' to act lawfully. Increasing procurement transparency, openness and impartiality, availability of information about specific procurements, achieving the maximum efficiency of purchase helps to reduce the risk.

\section{Conclusion}

In this work, criminal risks of the national public procurement system have been audited; typical criminal risks arising in all procurement stages both on the part of customers and on the part of other parties have been theoretically diagnosed.

It is important to note that the original hypothesis of an exclusively deliberate choice of criminal behavior has been confirmed in part. In many situations, the risk did not seem criminal to participants (ignorant awareness of legal prohibition and the rule of law, laissez-faire attitude, inflated ambitions). Participants mixed them with civil or 
administrative risks, had no notion of criminal liability danger and, therefore, acted rationally unreasonably. Opportunistic behavior also manifested through risk subjects' personal stereotypization caused by a) lack of experience, b) shortcomings of the mass media work, c) escalation of opinion about the number of abuses in this sphere. This kind of stereotypization leads to such negative consequences as the prejudices about criminal behavior as the only right way or to immaturity and assignment of responsibility to others.

The results put forward in our study have several implications. First of all, this article is based on theories of cross-sectoral importance (law, sociology, psychology). Crime pattern theories explain that crime is not a random phenomenon. Defining vulnerable factors of crime can help to determine the spatiotemporal patterns of criminal behavior, identify its underlying causes.

The authors believe that the study of risk behavior is an important factor in shaping the countermeasures to criminal behavior in the sphere of government order, improving the competitive procedures and the legislation. Simultaneously, it is essential to pay attention to the relationship subjective component. In this sense, it is necessary to intensify the work of legal education, to improve the work of the media and the judiciary. The authors are convinced that this can help law enforcement agencies use their resources more efficiently, thereby increasing their overall efficiency to combat crimes in public procurement.

Secondly, the authors are convinced that the risks themselves are important for predicting various forms of criminal behavior. The issues of understanding and tracking risk situations can help develop a better system of incentives, where a rational choice of public procurement participants will be made in favor of their compliance with the law at its every stage.

Of course, it is necessary to continue developing the study of criminal risks, particularly in relation to corruption and for the benefit of business communities.

\section{Acknowledgements}

The research has been sponsored by the Russian Foundation for Humanities in the framework of RFH research project 'Economic and legal risks of the Russian state and municipal procurement system: factors, evaluation, measures to reduce (localize)' No. 15-0200487.

\section{References}

1. Wells JT. Fraud Casebook Lessons from the Bad Side of Business. John Willey\& Sons, Inc: New Jersey. 2007.

2. Kovacich GL. Fighting Fraud: How To Establish And Manage An Anti-Fraud Program.1st (edn). Butterworth-Heinemann. 2007.

3. Davies G. Discrimination and beyond in European Economic and Social Law. Maastricht Journal of European and Comparative Law. 2011; 18(1):7-28.

4. Chambliss WJ, Michalowski R, Kramer R. State Crime in the Global Age. Routledge Publ.: London. 2013.

5. Giddens A. Fate, Risk and Security. In: Modernity and Self-Identity: Self and Society in the Late Modern Age. Stanford University: USA. 1991; 256 pp.

6. Luhmann N. Der Begriff Risiko. In: Soziologie des Risikos. Walter de Gruyter: Berlin; New York. 1991.

7. Beck U. Risk Society: Towards a New Modernity (Published in association with Theory, Culture \& Society) Paperback. Sage Publications: London, Newbury Park, New Delhi. 1992.

8. Ferwerda J, Deleanu I, Unger B. Corruption in Public Procurement: Finding the Right Indicators. European Journal on Criminal Policy and Research. 2016 May; 1-23.

9. Brantingham P, Brantingham P. Theoretical model of crime hot spot generation. Studies on Crime and Crime Prevention. 1999; 8(1):7-26.

10. Nechayev AD, Tishchenko EV. Criminal law risks in the sphere of discharging the obligations by the governmental and municipal contract parties. Terra Economicus. 2013; 11(3-2):176-83.

11. Risk Management in Public Procurement Process. Studies and Scientific Researches. Available from: https:// ideas.repec.org/a/bac/fsecub/10-15-62.html. Date Accessed:2010.

12. Zhalinsky AE. Criminal law in expectation of change: theoretical and instrumental analysis. Prospect Publ.: Moscow. 2009. [in Russian]

13. Kudryavtsev VN. Causality in Criminology. Yurid. Lit. Publ: Moscow. 1968. [in Russian]

14. von Mises L. Human Action: A Treatise on Economics. Graves BB (Ed.) (4th revised ed.) Irvington-on-Hudson: Foundation for Economic Education. 1996. Available from: http://oll.libertyfund.org/titles/mises-human-action-atreatise-on-economics-fee-ed

15. Svensson J. Eight questions about corruption. The Journal of Economic Perspectives. 2005; 19(3):19-42. Doi: $10.1257 / 089533005774357860$. 